\title{
Lineamientos generales para una nueva estrategia de industrialización
}

\author{
Roberto Rubio
}

En este articulo se ofrecen algunos lineamienlos generales que puedan servir a la elaboración de una estrategia de industrialización sobre nuevas bases. Se busca con ello proporcionar un conjunto de ideas en torno al tipo de industrialización que debería impulsarse en nuestro país. Esperamos contribuir a perfilar un horizonte, un marco de relerencia desde el cual distintos agentes de la sociedad salvadorefía puedan buscar consensos posibles y necesarios en lorno a la problemálica de la industrialización.

Podemos comenzar preguntándonos ¿es necesaria una nueva estralegia de industrialización? El fracaso y/o limitaciones de las estrategias de industrialización predominanles en los paises mal-desarrollados (de sustilución de importaciones o de promoción de exportaciones, entre las más relevantes), plantea la conveniencia de elaborar una estrategia de desarrollo industrial sobre bases distintas.

Más aún, podemos inclusive hablar de cierto fracaso, 0 al menos de graves deformaciones, de las estrategias de industrialización vigentes en los llamados paises del Norte. $Y$ aunque este fracaso/deformación a escala nacional no sea tan evidente para muchos y constiluya importante objelo de debate (a pesar de lodos los males que la modernidad ha ido creando: secuelas de desempleo, cinturones de pobreza, deterioro de la calidad de vida, delincuencia, elc), lo que si aparece con mayor claridad es su fracaso a escala planetaria. Baste traer a cuenla dos grandes fenómenos terrícolas de la era actual, que cuestionan profundamente la viabilidad hislórica del imperante modelo anglo-sajón de industrialización: 
el grave deterioro planetario del medio ambiente y la alarmante separación Norte-Sur. Alejados momentáneamemle los peligros de la bomba nuclear, la modernidad actual, y los patrones de industrialización que la acompanan, ha ido construyendo dos bombas con parecido poder destructivo: la "bomba ecologica" que amenaza hacer estallar el habilat humano y la "bomba social" que está haciendo lo mismo con la convivencia humana dentro y entre las naciones.

Los requerimientos de nuevos estilos de industrialización se hacen más patentes frente a la carencia de alternativas viables y diferentes de las que surgen del omnipresenle modelo neo-liberal.

Frente a lo anterior, se hace imperativo mostrar que existen otras pollticas de industrialización más allá del "ajuste estructural". Es preciso negar la supuesta universalidad de las estrategias de industrialización predominantes. Hay que ir al encuentro de nuevas estrategias de industrialización.

Ahora bien, todo ello exige nuevas respueslas a viejas interrogantes ( $y / 0$ la formulación de nuevas preguntas): ¿Orientamos el aparato industrial hacia el mercado externo o al interno? ¿Qué tipo de técnicas y bienes deberá priorizar un proceso de industrialización? ¿La expansión industrial se hace en forma centralizada, por medio de polos de desarrollo, o de manera descentralizada? ¿Sobre qué sectores se apoya la industrialización y bajo qué modalidades to hace? La respuesta a semejantes cuestiones contribuirá a pertilar nuestra estrategia de industrialización para EI Salvador de la post-guerra.

\section{La estrategla general de Industriallzaclón. Princlplos nomatlvos}

A grandes rasgos, el pertil de nuestra estrategia de industrialización se plantearía en los siguientes términos.

1.1. La expansión industrial estará preferencialmente orientada hacia la dinámica interna (sin excluir la promoción de exporlaciones), tenderá a fortalecer prioritariamente el sector agropecuario y el sector de servicios básicos, y priorizará todas aquellas actividades vinculadas a la salisłacción de las necesidades básicas de las mayorias.

1.2. La expansión industrial se basará no sólo en la aplicación adecuada de técnicas modemas (sobre lodo adecuada al mantenimiento de los equilibrios del ecosistema) sino también en la incorporación creativa y pertinente de técnicas "Iradicionales", dentro de lo cual la "economia popular", la pequeha empresa y el artesanado rural y urbano deberán jugar un papel de primer orden. De la misma manera, nuestra eslrategia 
de industrialización conlempla no sólo la producción de "bienes modernos" (más acordes a las exigencias e intereses del mercado internacional) sino que también Irata de integrar la producción de "bienes no modernos" (más en sintonia con las necesidades, rasgos e intereses de la economía nacional).

Los dilemas de polílicas en torno a las técnicas intensivas en capital - Irabajo, o los que giran sobre la producción de bienes de capilal, intermedios o de consumo, deben ser resueltos sobre la base de las realidades nacionales, regionales o locales concrelas, o de la especificidad de las actividades productivas en cuestión. Por tanto no pueden haber polílicas nacionales y uniformes al respecto.

1.3. La industrialización no debe poseer un carácter concentrado y exclusivamente urbano. La dinamización de la industria se realizará decentralizadamente y no será discriminatoria con el mundo rural. Todo ello en el marco de lo que podremos detinir como un impulso al "microdesarrollo", como complemenlo necesario a los grandes, y muchas veces costosos, inadecuados y megalómanos proyectos del "macro-desarrollo" (dentro de los que el Cerrón Grande es buen ejemplo).

1.4. El proceso de industrialización no debe basarse en el sometimiento del sector agrario. La producción de alimentos y materias primas, la olerla rural de fuerza de Irabajo, los fondos de inversión o divisas provenientes del seclor agropecuario no deben estar funcionalmente al servicio de la industrialización. El apoyo que busca la industrialización no es de sometimienlo sino de cooperación con el seclor agrario. Una cooperación que eslá en lunción de la agroindustrialización. En este sentido, y de manera semejante a lo que ocurrió con el proceso de industrialización de la China en la época maoista, es más la industria la que está al servicio de la agricultura que ésla al servicio de la primera.

\section{Elementos de sustentación de la estrategla general de industrla- lización}

He aqui más en detalle algunos de los principios y análisis que suslentan la estrategia general de industrialización recién esbozada.

Algunos principios/lineamientos que integran nuestra estrategia de industrialización podemos extraerlos por el "método de deliniciones negalivas". En efecto, exponiendo lo que no debe ser o contener una estrategia de industrialización podemos ir mostrando la idea diterente que lenemos de la misma. 
2.1. Industrializarse no es sólo equivalente a expansión del sector industrial. Una "industrialización cerrada", sin ampliación/penetración de los dos seclores vitales de nuestra economía (agro y servicios), es una industrialización limitada. Industrializarse no es solamente producción de bienes industriales para la industria, o para el mercado externo, sino también producción de bienes que tienden a incrementar la capacidad de expansión, transtormación y mejora de las actividades agropecuarias y los servicios básicos (salud, educación, vivienda, comunicaciones, intraestruclura). En lal sentido, un proceso de industrialización prioritariamente volcado al mercado externo, una expansión industrial "de espaldas" a los vitales sectores agropecuario y de servicio básicos, más allá de las debilidades que en sí confronta (como lo veremos más adelante), es un proceso de induslrialización limitado/deformado.

De tal forma que un proceso de industrialización es también equivalenle a la agroindustrialización (en especial), al desarrollo del artesanado rural y umano, a la potenciación o mejora cualitativa de la llamada economía inlormal, al crecimiento y mejora cualitativa en los equipamientos o servicios básicos, etc.

2.2. La industrialización no significa el crecimiento exclusivo de la industria moderna (y su correlato: la desaparición de la pequefia industria y artesanado "no moderno"). Un proceso de industrialización es compatible con la expansión de la pequena industria y el artesanado urbano y rural.

En consecuencia, industrializarse no implica sólo la aplicación de las llamadas técnicas modernas. Es más, una "mala industrialización" puede ser producto de la implementación de las mismas. Es el caso de las técnicas modernas de construcción en serie que atenlan contra el confort o el ecosistema (muchas de las urbanizaciones que proliferan en San Salvador hoy en día son buen ejemplo de ello), o de la utilización de maquinaria especializada en la producción de bienes lextiles standar que afecta nocivamente la creatividad y salud de los obreros pertenecientes a la cadena.

Por tanlo, un proceso de industrialización puede ser compatible/complementado con la aplicación de técnicas "atrasadas" o tradicionales": producción artesanal de ladrillo/adobe/leja, polenciación y cualificación de una red de sastres y zapateros, por ejemplo.

Asimismo, si la industrialización no es sólo la aplicación de técnicas modernas, tampoco lo son sus resultados, es decir la producción de bienes modernos. En electo, muchos de estos bienes son valorizados acorde a la demanda inlernacional y/o a los "patrones de consumo inter- 
nacional" y no por las necesidades e intereses de las mayorías nacionales. Por tanto, también la producción/expansión de ciertos bienes modernos puede ser expresión de una "mala induslrialización", como sucede dentro de la producción de azúcar refinada, producción de medicamenlos químicos, producción de zapalos y texliles en serie. Asl por ejemplo, el contenido y lorma de los zapalos y muchas prendas de vestir modernas, eslán delerminados por parámetros que corresponden a estilos de vida de paises con altos niveles de consumo, donde la durabilidad del producto es un criterio de menor peso (pesan más otros criterios como la forma, la moda, el color, etc).

En base a lo anlerior podemos alirmar que una "buena" industrialización es compatible con la producción de bienes industriales "no modernos" o tradicionales: producción de azúcar morena o no refinada (aparenlemenle menos cara y más saludable), producción de medicamentos por medios no químicos (en base a plantas medicinales por ejemplo), producción de zapalos y vesluario a la medida (con mayor durabilidad o adaplabilidad al medio).

Por último, valga senalar que normalmenle las técnicas y bienes industriales modernos son portadores de altos coeticientes de importación. Mientras que los "bienes tradicionales/artesanales" suelen recurrir a una mayor utilización de los recursos locales. Por lo que un proceso de industrialización que amplíe, combine y aplique adecuadamente las técnicas y bienes "Iradicionales" junto con las modernas (las que se adecuen al contexlo nacional), lenderá a reducir los niveles de dependencia de las importaciones. Esto signilica impulsar un proceso de industrialización con luerza eslabilizadora para los equilibrios macroeconómicos.

Como se notará, nuestra idea de industrialización amplía las interrogantes sobre el tipo general de técnica y tipo general de bienes a priorizar. No sólo se trala de decidir si son procesos de trabajo intensivos en capital o intensivos en trabajo, de si hay que privilegiar la producción de bienes de consumo, intermedios o de capilal. Se trata de dar respueslas también en términos de la elección de patrones tecnológicos y calidad de los bienes industriales, es decir en lérminos de tipos especificos de técnicas y bienes.

Pero nuestra eslralegia de industrialización tiende también a dar respuesta a los tipos generales de técnicas y bienes que deben priorizarse. A grosso modo podria afirmarse que, dadas las condiciones del pais (abundancia de mano de obra sobre todo), deberá privilegiarse la utilización de técnicas intensivas en trabajo y la producción de bienes de consumo. 
Sin embargo, se trala de un lineamiento que deberá matizarse y aplicarse discriminadamente. En efecto, en ciertos casos, en ciertas actividades (sobre todo en las empresas o ramas industriales más abierlas al exterior), convendrá el uso de técnicas intensivas en capital. Por otra parte, delerminadas políticas o proyectos de desarrollo exigirán dar preferencia a la producción de bienes de capital ligeros (no siempre cuando se piensa en bienes de capital hay que asociarlo a grandes y complejas máquinas): equipamientos para pequenas obras de irrigación, instrumentos manuales de trabajo, equipos de saneamiento o de salud, etc. Por ello afirmamos en la presentación de nuestra eslrategia general que esta clase de interrogantes "clásicas" de la industrialización deberán ser respondidas de acuerdo a la diversidad espacial, geográfica, económica, etc. de nuestro país.

2.3. El proceso de industrialización no se reduce o no significa solamente la creación de grandes complejos industriales concentrados en el área urbana y/o capitalina. Ante las desventajas que presenta la ya alla concentración y centralización del parque industrial en San Salvador, y de las ventajas que contiene la descentralización industrial (en lérminos de mejoras en la articulación productiva, equilibrios regionales, aprovechamiento de recursos locales, etc.), la expansión industrial debe llegar a todo el territorio y debe entenderse no sólo en parámelros nacionales sino lambién regionales y locales.

Hay que abandonar la idea de la industrialización por medio de polos de desarrollo que posteriomente irradiarán sus efectos benélicos sobre sus alrededores. La descentralización no significa crear "islas" regionales (un par de polos industriales por departamento o unos cuantos por región). Los polos industriales no garanlizan por sí mismo el desarrollo de su entorno. Al contrario, pueden llevar a la desarticulación o deterioro de la mediana/pequena empresa y de las débiles redes del artesanado rural.

En tal contexto, industrialización signilica también induslrialización del medio rural. Industrializarse implica además desarrollar industrialmente el entorno regional y local. La descentralización industrial no sólo comprende la creación de complejos industriales o grandes/medianas empresas en el medio rural o en ciudades importanles, sino también la expansión de empresas regionales/zonales y el impulso de micro-empresas o micro-proyectos locales, gestados y administrados por las comunidades o fuerzas sociales locales/zonales. Se puede y deben crear pequenos o medianos estuerzos de procesar industrial o artesanalmenle la producción local/zonal, elaborar moderadas obras de ingeniería para la producción energélica, disefar pequefias o medianas plantas de produc- 
ción de abono orgánico o insumos en general, impulsar la constitución de lalleres locales/zonales para la elaboración de equipo o instrumentos de trabajo ligeros, etc.

Bajo ese cuadro de la "industrialización simple", por ejemplo, la solución a la crisis energética del pals no pasa sólo por los cánones del macro-desarrollo, con la creación de otra gran represa o la compra de grandes turbinas movidas por derivados del peiroleo, sino que también se viabiliza por los circuilos del micro-desarrollo y de la economia popular, con la construcción de pequenas obras hidroeléctricas, utilización de la bio-masa, elc.

Valga senalar que este tipo de indusırialización, articulado adecuadamente con la industria nacional y/o moderna, es un proceso que contribuirá a la reducción de las importaciones y fomento de las exportaciones, al mantenimiento de los equilibrios del ecosislema, a la eficacia productiva, a la articulación inter e intra sectorial, al mejor aprovechamiento de los recursos nacionales y a la potenciación de la capacidad de gestión y organización de los sectores populares.

2.4. El proceso de industrialización no se sostiene o basa en el sometimiento del sector agropecuario. La industrialización no se apoya en la transterencia unilateral de excedentes del agro a la industria, como ha sido el comportamiento clásico. En nuestro país, la economla campesina productora de granos básicos ha sostenido las necesidades alimenticias-salariales del crecimiento induslrialurbano, los requerimientos industriales en divisas se han apoyado en la agroexportación, los abastecimientos de mano de obra se han nutrido de los desequilibrios surgidos del binomio latifundio-minifundio. El sesgo anti-agricola que ha marcado el desarrollo industrial en nuestro país (reconocido por los mismos programas de estabilización y ajuste esinuctural, aunque valorado con otros criterios) ha sido causa importante del grave mal-desarrollo que históricamente ha presentado el sector agropecuario en El Salvador.

La política de promoción de exportaciones agrarias no tradicionales del presente gobiemo, como nueva fuenle de generación de divisas necesarias al proceso de induslrialización, no logra salir del clásico esquema de impulsar el proceso de industrialización por medio del sometimiento del sector agropecuario (sin olvidarnos de las debilidades y limitaciones que conlleva en si la estralegia de promoción de exportaciones agrarias no tradicionales). En consecuencia, una adecuada estrategia de industrialización no puede apoyarse en la translerencia unilateral de excedentes y recursos del sector agropecuario, no puede llevarse a cabo a costa del sacrificio del desarrollo rural (en un país donde las actividades agropecuarias son determinantes). 
Ahora bien, si la industrialización no se apoya en las transferencias unilaterales del sector primario ¿puede y debe apoyarse sobre la dinámica interna del sector induslrial? Si el sector agropecuario no es la fuente fundamental de las divisas que necesita la industrialización ¿puede convertirse la industria en dicha fuente, a través de una estrategia de promoción de exportaciones de bienes industriales?. Es decir, ¿podemos apostar por una estralegia de industrialización basada en la extroversión del aparato industrial?

Creemos que no. He aqul algunas de las razones de nuesira negativa: 1 . Se corre el riesgo de continuar con el sesgo anli-agrícola. 2. Se reducen, al menos a medio plazo, las posibilidades de induslrialización de la agricultura. 3. Se podría favorecer la desarticulación inter-sectorial. 4. Existen mayores y a veces insuperables dificultades para competir en el mercado intemacional de bienes industriales. 5. Hay serias limilaciones para la obtención de la mano de obra calificada y lecnologia que exige la producción de bienes industriales transables con el mercado internacional. 6. Se corre el peligro de entrar en un proceso de transnacionalización no controlable. 7 . Se incrementan los riesgos de utilización de lecnología inapropiada.

Si una estrategia de induslrialización no se apoya en el somelimiento del sector agropecuario, y si lampoco se puede basar sólo en la dinámica induslrial ¿dónde eslán las bases de apoyo y orienlaciones fundamentales de nuestra estrategia de industrialización?

Tales bases y orientaciones las encontramos en los siguientes planteamienlos.

-El proceso de industrialización, más que someter el seclor agropecuario, debe estar prioritariamente encaminado a promover la industrialización de dicho seclor. La agroindustrialización se convierte así en el eje fundamenlal de nuestra estrategia.

-En segunda prioridad, el proceso de industrialización debe encaminarse a la producción de bienes y equipamienlos necesarios a la ampliación y mejora de los servicios básicos.

-Nuestra estrategia de industrialización, de cara a los requerimienlos en divisas, no se apoya o concentra en un sector particular, sea esle el agropecuario, o el industrial. El apoyo sectorial en divisas deberá ser adecuadamente compartido lanto por las actividades agropecuarias como por las industriales y/o artesanales (así como algunos servicios, dentro de los que destaca el turismo). Valga indicar, que en el corto o mediano plazo, las necesidades en divisas para apoyar la industrialización pueden y deben también apoyarse en la caplación y mejor utiliza- 
ción de las remesas de los salvadorenos residentes en el exterior, asi como en los fondos externos que parecen vendrán en sostén del proceso de reconsinucción.

- Una politica de promoción de exportaciones industriales no debe perder de vista que la orientación fundamemal de la estrategia de industrialización es la salisfacción de las necesidades básicas de las mayorlas y la mejora de la calidad de vida de los salvadorenos de hoy y del manana.

-Asimismo, una polílica de promoción de exportaciones industriales, dado el poco margen (intencional u objelivo) de incrementar la "competitividad" por medio de mecanismos salariales o de incorporación de tecnología modema, deberá sustentarse en otras variables o principios. Cabe destacar la integración adecuada del principio de las "ventajas comparativas dinámicas". Esto implica, al menos, la puesta en marcha de procesos de producción industrial más flexibles y creativos, y un moniloreo más efectivo y detallado de los mercados internacionales de diversos productos. En este sentido podemos resaltar las posibilidades que tienen productos como los textiles, los farmacéuticos a base de plantas medicinales, los productos artesanales (artesanía en sentido amplio), muchos productos agroindustriales, los abonos orgánicos, elc.

-Un proceso de industrialización "apropiado y apropiable" podría ser compatible con la búsqueda de apoyo de la inversión extranjera. Siempre y cuando ésta encaje con los contenidos y objetivos de nuestro proyecto nacional. En este marco, y sólo dentro de él, cabe el eslablecimienlo de las "joints-ventures", las zonas francas, las sub-contralaciones con empresas multinacionales, etc.

- Un factor importante en el que podria apoyarse nuestros esfuerzos de induslrialización es la cooperación regional y el eslablecimiento/promoción de proyectos de inversión a escala centroamericana. Hoy por hoy una politica marginal dentro de los programas integracionistas. 